\title{
Study on stress evolution in the cooling process of micro hot embossing
}

\author{
Juan A Gomez ${ }^{1}$, Devanda Lek ${ }^{2}$, In-Hyouk Song ${ }^{1,2}$ and Byoung Hee You ${ }^{1,2^{*}}$
}

\begin{abstract}
Cooling of an embossed part has been recognized as one of the critical steps in the hot embossing of polymer microdevices. Numerical analysis was performed to study the stress developed in an embossed microstructure during the cooling process of hot embossing. A hemisphere-tipped post was selected as an example structure to demonstrate the stress evolution. The posts are located at 5, 10, 15, and $20 \mathrm{~mm}$ from the center of the embossed part. The results of the analysis showed that stresses of the posts increased as the radial locations of the post increased. In addition, the stress rapidly increased until the cooling time reached about $100.0 \mathrm{~s}$. The maximum stresses of 28.9, 30.2, 32.3, and $34.5 \mathrm{MPa}$ were estimated at the post locations of 5, 10, 15, and $20 \mathrm{~mm}$ from the center of the part, respectively. Experiments were performed to verify the numerical models. Undercut at the bottom of a post was observed as it was predicted in the numerical analysis.
\end{abstract}

Keywords: Cooling; Micro hot embossing; Stress evolution; Shrinkage; Stress concentration

\section{Review}

Cooling of a molded part is a critical step for the successful fabrication of polymer microstructures using hot embossing (Matthew and David 2011; Song et al. 2008a; Jeong et al. 2002). Defects not caused by the filling of the mold cavity with polymer are attributed to the cooling or demolding process (Song et al. 2008a; Jeong et al. 2002; Guo et al. 2007a, b). Typical cooling defects include distorted, deformed, and broken microstructures. The shrinkage of polymer induces thermal stress in the molded part as it cools down. Thermally induced mechanical stress is a principal contributor to the defects (Song et al. 2008b; Worgull et al. 2008; Schift et al. 2001). Numerical analysis can assist in understanding the stress evolution and the defects since the observation of microstructure is extremely difficult during cooling.

Hot embossing consists of heating a polymer substrate above its glass transition temperature, pressing a mold insert into the polymer substrate to transfer the features, cooling the substrate and mold insert while maintaining the embossing pressure, and separating the mold insert

\footnotetext{
* Correspondence: by12@txstate.edu

'Materials Science, Engineering, and Commercialization Program, Texas State University, San Marcos, TX 78666, USA

${ }^{2}$ Department of Engineering Technology, Texas State University, San Marcos, TX 78666, USA
}

from the polymer substrate (Matthew and David 2011; Song et al. 2008a). Compared with microinjection molding, hot embossing offers advantages such as low operation cost, process simplicity, and easy mold exchange as well as replicating structures with a lower internal residual stress (Guo et al. 2007a, b; Song et al. 2008b; Worgull et al. 2008).

Numerical analyses and experiments have been performed to understand the evolution of stress on a polymer substrate during molding. Dirckx et al. showed the effects of thermal stress, friction, and adhesion on the defects of the molded part (Matthew and David 2011). Adhesion and friction between the sidewall of the mold cavity and the molded part played a significant role during demolding.

Thermal shrinkage and adhesion forces were analyzed by the finite element method (FEM) to decrease the thermal stress of molded structures (Guo et al. 2007a, b). The deformation of microstructures typically occurred in both the cooling and demolding steps. Numerical simulations estimated the friction force generated by adhesion and thermal stress (Guo et al. 2007a; Song et al. 2008b). Thermal stress was correlated with the geometry of a mold cavity, and auxiliary structures on the molded part were suggested as thermal stress barriers (Worgull et al. 2006; Farshchian et al. 2012).

\section{Springer}


In this paper, the stress evolution of a molded structure was studied during the cooling process of hot embossing. Numerical analysis was performed using the commercial finite element method software DEFORM2D (Scientific Forming Technologies Corp., Columbus, $\mathrm{OH}, \mathrm{USA})$. A hemisphere-tipped post used in previous microassembly studies was selected as an example structure for the numerical analysis. Hot embossing experiments were also performed to verify simulation. The results of simulation and experiments showed the defects that resulted from thermal stress of the post.

\section{Numerical analysis}

DEFORM-2D has been used in hot embossing simulations (Farshchian et al. 2012; You et al. 2009; Jin et al. 2009). The flow of polymer was assumed as a nonNewtonian viscous fluid in demolding. The flow stresspolymer temperature relationship was described by a segmented linearization obtained from experimental data (Juang et al. 2002a, b). Flow stress of the polymer was defined as the function of stress and strain under constant strain rates. Equation 1 defines the flow behavior of the polymer at given molding temperatures and embossing forces:

$$
\sigma=c T+\varepsilon^{k}
$$

where $\sigma$ is the flow stress, $T$ is the molding temperature, $\varepsilon$ is the strain rate, and $c$ and $k$ are the coefficients for the molding temperatures.

Heat transfer between the boundaries of the polymer substrate, the mold insert, and the substrate plate were defined as thermal conductivity in the numerical analysis as represented in Equation 2. Equation 2 defines the heat transfer rate between objects in thermal contact:

$$
q_{\text {cond }}=-C_{\text {cond }} \frac{\partial T}{\partial X}
$$

where $q_{\text {cond }}$ is the heat flux generated by conduction, $C_{\text {cond }}$ is the thermal conductivity coefficient, and $\frac{\partial T}{\partial X}$ is the temperature gradient.

The effect of heat transfer between the environment and the polymer substrate was considered by convection as presented in Equation 3. Equation 3 defines convection cooling as the heat transfers relative to the difference in temperatures between the polymer substrate and the environment:

$$
\frac{d q_{\mathrm{conv}}}{d t}=h A\left(T(t)-T_{\mathrm{env}}\right)=h A \Delta T(t)
$$

where $q_{\text {conv }}$ is the heat transfer associated with convection, $h$ is the heat transfer coefficient, $A$ is the surface area, $T$ is the substrate temperature, $T_{\text {env }}$ is the temperature of the environment, and $\Delta T(t)$ is the time-

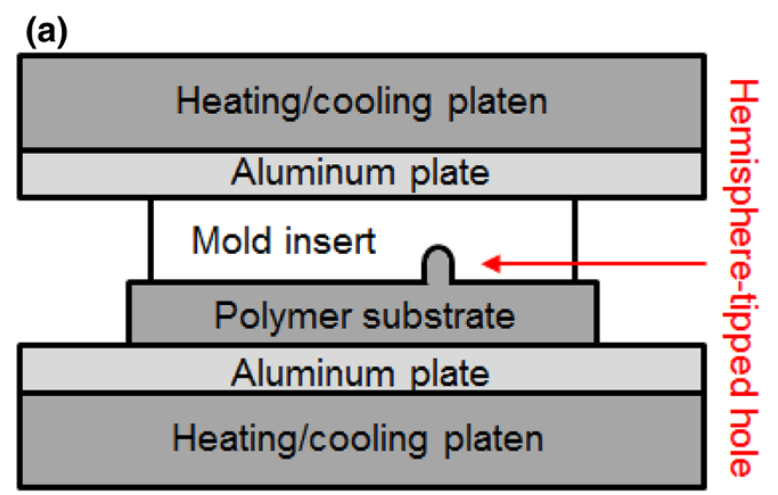

(b)

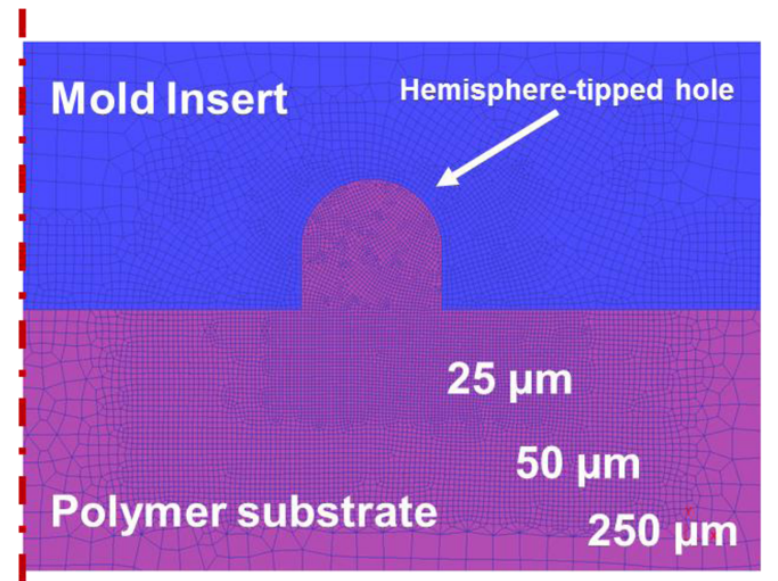

Figure 1 Schematic of hot embossing setup and the finite element model for the cooling process of hot embossing. (a) Schematic of the hot embossing setup and (b) finite element model for the cooling process of hot embossing.

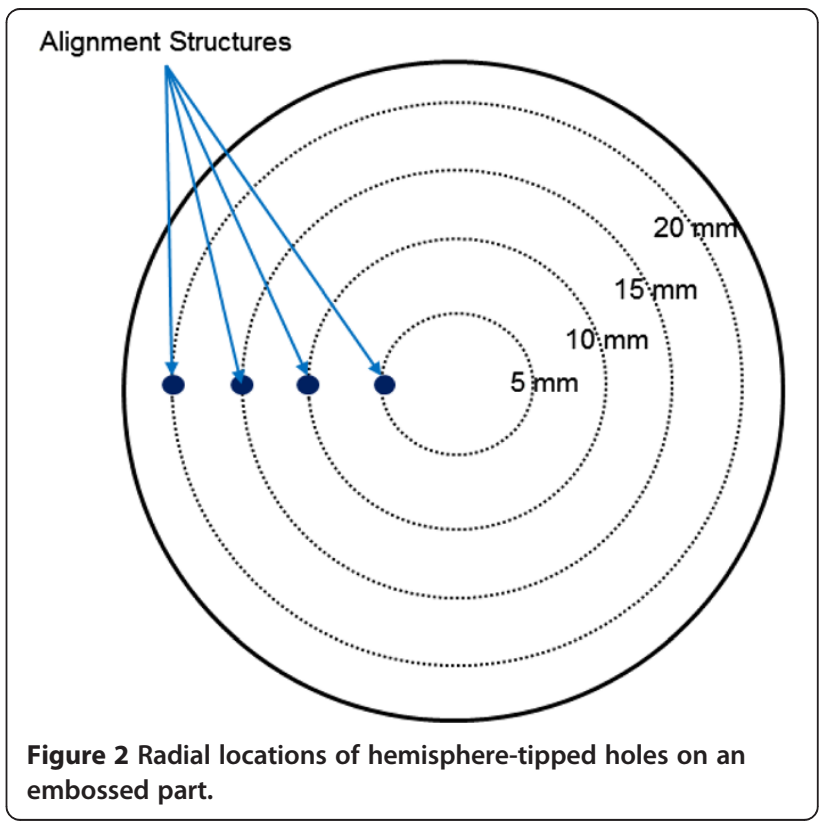


Table 1 Material and process parameters in experiments

\begin{tabular}{lc}
\hline Material & PMMA \\
\hline Density $\left(10^{3} \mathrm{~kg} / \mathrm{m}^{3}\right)$ & 1.19 \\
$\mathrm{Tg}\left({ }^{\circ} \mathrm{C}\right)$ & 108 \\
Embossing temperature $\left({ }^{\circ} \mathrm{C}\right)$ & 150 \\
Cooling time $(\mathrm{s})$ & 900 \\
Demolding temperature $\left({ }^{\circ} \mathrm{C}\right)$ & 85 \\
\hline
\end{tabular}

dependent thermal gradient between the environment and the polymer substrate.

A schematic of the hot embossing setup and the finite element model for numerical analysis are shown in Figure 1. Figure 1a represents the typical hot embossing configuration for simulation. The cooling process of the hot embossing was modeled as a non-isothermal and axis-symmetric system as shown in Figure 1b. A mold insert had hemisphere-tipped holes corresponding to a hemisphere-tipped post. The alignment structure, a hemisphere-tipped post, had a depth of $952 \mu \mathrm{m}$ and a radius of $500 \mu \mathrm{m}$.

The mold insert, the aluminum plates, and the platens were considered as rigid bodies. The polymer substrate was considered an elasto-plastic body. Heat exchange boundaries were included to the mold insert, aluminum plates, and polymer substrate to allow heat transfer between thermal contacts and the environment. It was assumed that the polymer flows identically in any cross-sectional area on the $X$ - and $Y$-planes. A non-slip condition was applied on the bottom surface of the polymer substrate.

The simulation model included 9,700 four-nodal elements for the polymer substrate. The element size decreased from 250 to $25 \mu \mathrm{m}$ as the polymer substrate reached the boundary of the hemisphere-tipped hole. During cooling, the mold temperature was decreased from $150^{\circ} \mathrm{C}$ to $85^{\circ} \mathrm{C}$. A cooling time of $900 \mathrm{~s}$ was considered in the numerical simulations.

Four radial locations of the post at $5,10,15$, and $20 \mathrm{~mm}$ from the center of the mold insert were considered to evaluate whether the radial location of the post had an effect on the stress evolution as shown in Figure 2. The polymer substrate was assumed to completely fill the hemispheretipped hole. Thus, the cooling step will initiate from the assumption that the mold cavity is completely filled.

\section{Experiments}

A Carver thermal press (AutoFour/15-NE, Carver, Inc., Wabash, IN, USA) was used for hot embossing experiments. The mold insert, having hemisphere-tipped holes,
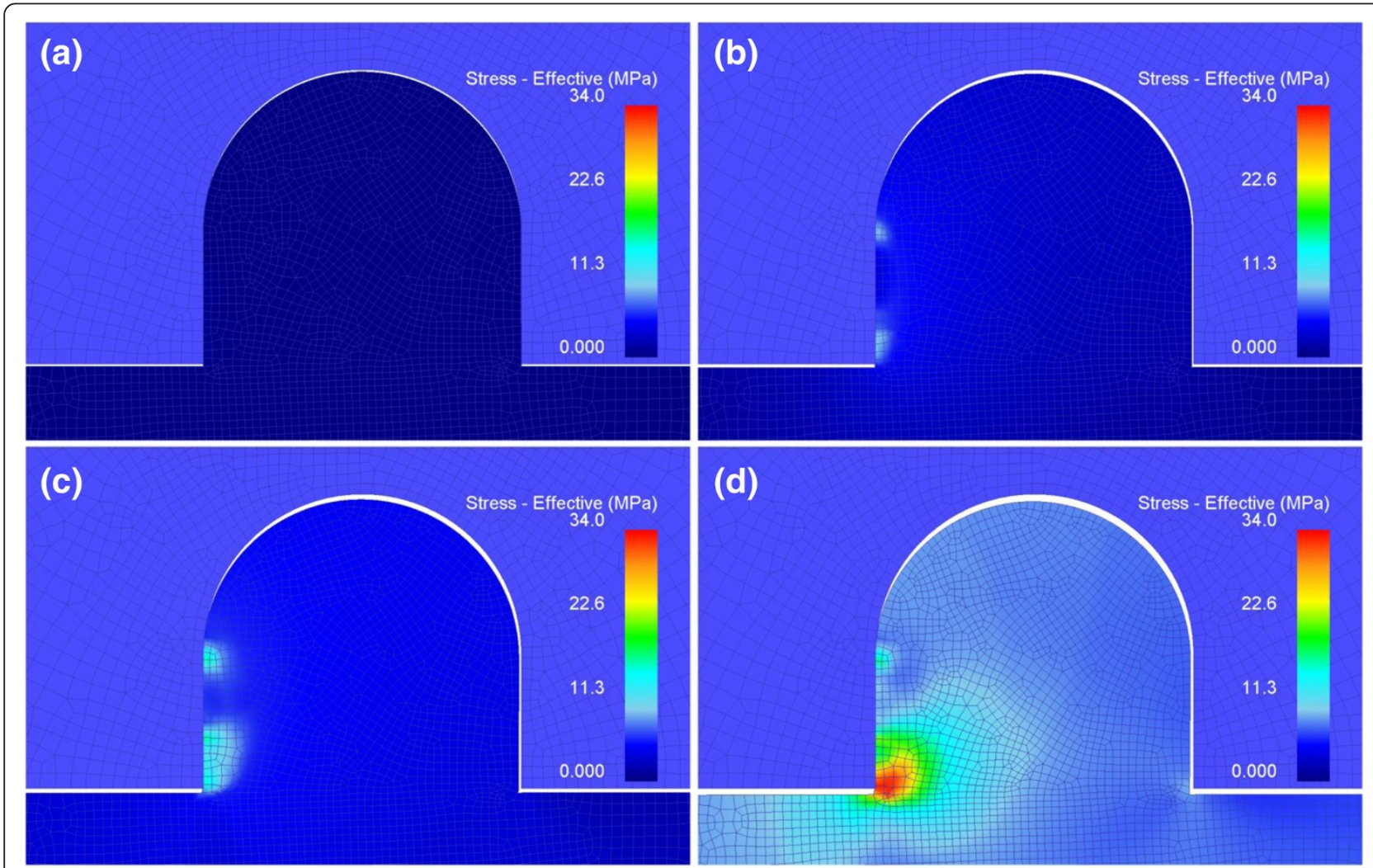

Figure 3 Stress evolution of the post located $5 \mathbf{~ m m}$ from the thermal center during cooling. (a) Cooling time of $1.1 \mathrm{~s}$, (b) cooling time of $5.1 \mathrm{~s}$, (c) cooling time of $10.6 \mathrm{~s}$, and (d) cooling time of $56.1 \mathrm{~s}$. 
was mounted at the center of the upper aluminum plate. The polymer substrate was placed on the lower aluminum plate during molding. Poly(methyl methacrylate) (PMMA) sheets (Plexiglass ${ }^{\oplus}$ Sabic Plastics, Shanghai, China) were selected as the substrate material. The thickness of PMMA was $4.5 \pm 0.5 \mathrm{~mm}$. The glass transition temperature of PMMA is about $105^{\circ} \mathrm{C}$. Prior to embossing, the polymer substrates were dried in a convection oven (31-350ER-1, Quincy Lab, Chicago, IL, USA) for $4 \mathrm{~h}$.

Material and process conditions applied in the experiments are shown in Table 1. Molding temperature was $150^{\circ} \mathrm{C} \pm 5^{\circ} \mathrm{C}$, embossing force was $600 \mathrm{~N}$, cooling time was $900 \mathrm{~s}$, and demolding temperature was $85^{\circ} \mathrm{C} \pm 5^{\circ} \mathrm{C}$. Scanning electron microscopy (SEM; Helios NanoLab 400, FEI, Hillsboro, OR, USA) was used to take the image of molded structures.

\section{Results and discussion}

Numerical analyses were performed to investigate the stress evolution of the embossed post during cooling. The results of these analyses were represented by effective stress of the molded posts at cooling times of about 1, 5, 10, and 55 s. Different colors represent the distribution of effective stress of the post.
Figure 3 shows the stress of the post located $5 \mathrm{~mm}$ from the center of the part. The shrinkage of the part began from the top surface of the hemisphere-tipped post with the cooling of polymer as shown in Figure 3a. The stress in the post was developed along the left sidewall of the mold cavity at a cooling time of $5.1 \mathrm{~s}$ as shown in Figure 3b. The post was separated from the right sidewall of the mold cavity as the shrinkage of polymer increased. Figure $3 \mathrm{c}$ shows the stress concentration on both the top and bottom of the sidewall of the post with the cooling time of $10.6 \mathrm{~s}$. The maximum stress of $33.3 \mathrm{MPa}$ was observed in the vicinity of the bottom edge of the post following the direction of the thermal center when the cooling time was $56.1 \mathrm{~s}$ as shown in Figure 3d.

The stress developed in the post, located $20 \mathrm{~mm}$ along the radial direction of the part, is shown in Figure 4. The increase in radial distance of the post from the center induced a higher stress to push the post in the opposite direction of the shrinkage of polymer. This caused the inclination of the post as shown in Figure $4 \mathrm{~d}$. The stress was concentrated on the left bottom edge and it expanded further into the post as the cooling time increased. This resulted in the undercut of the post at its bottom edges. The maximum stress of $34.6 \mathrm{MPa}$ was estimated at a cooling time of $55.5 \mathrm{~s}$.
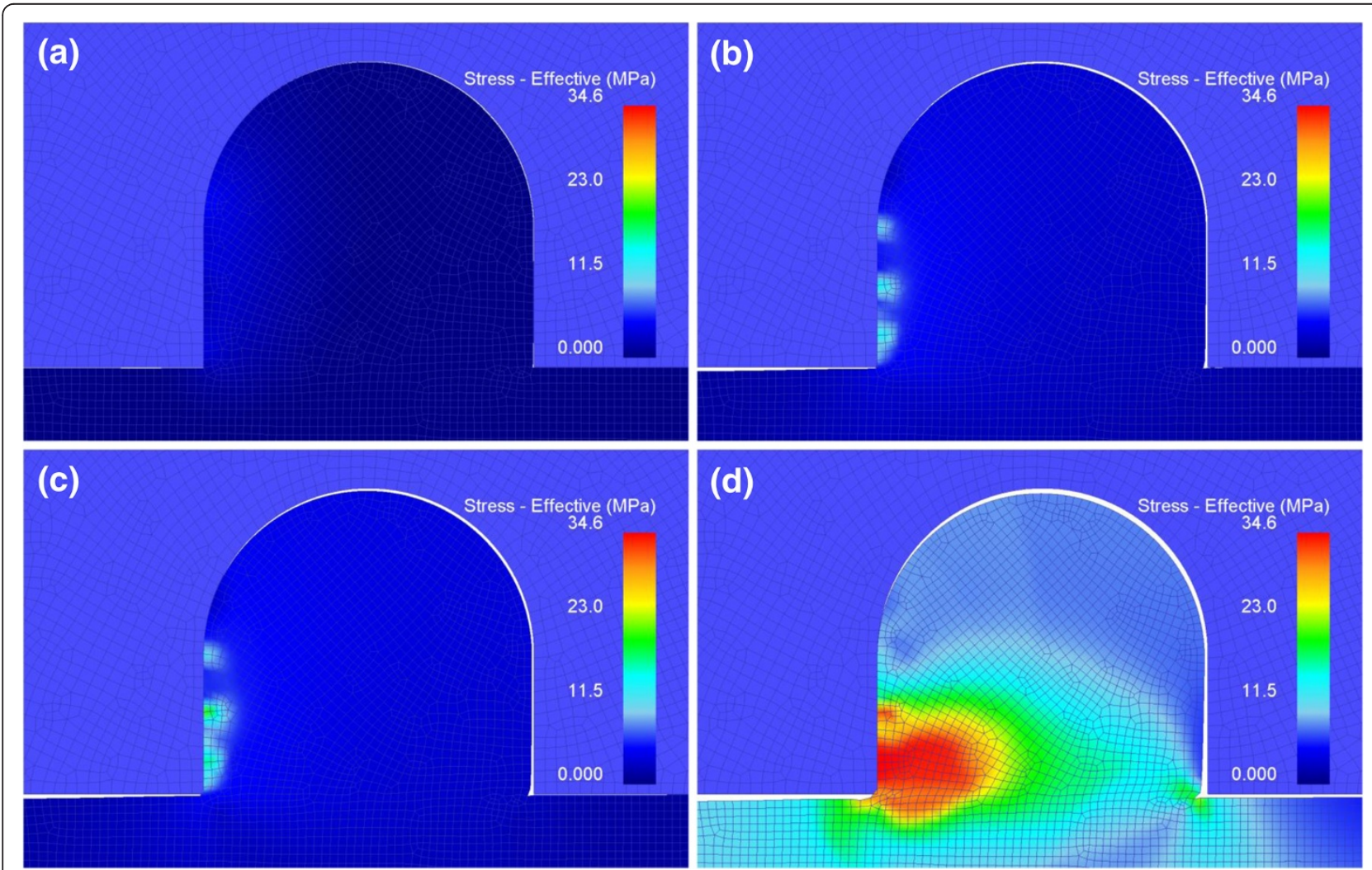

Figure 4 Flow stress of the alignment structure located $20 \mathrm{~mm}$ from the thermal center during cooling. (a) Cooling time of $1.0 \mathrm{~s}$, (b) cooling time of $5.0 \mathrm{~s}$, (c) cooling time of $10.2 \mathrm{~s}$, and (d) cooling time of $55.5 \mathrm{~s}$. 


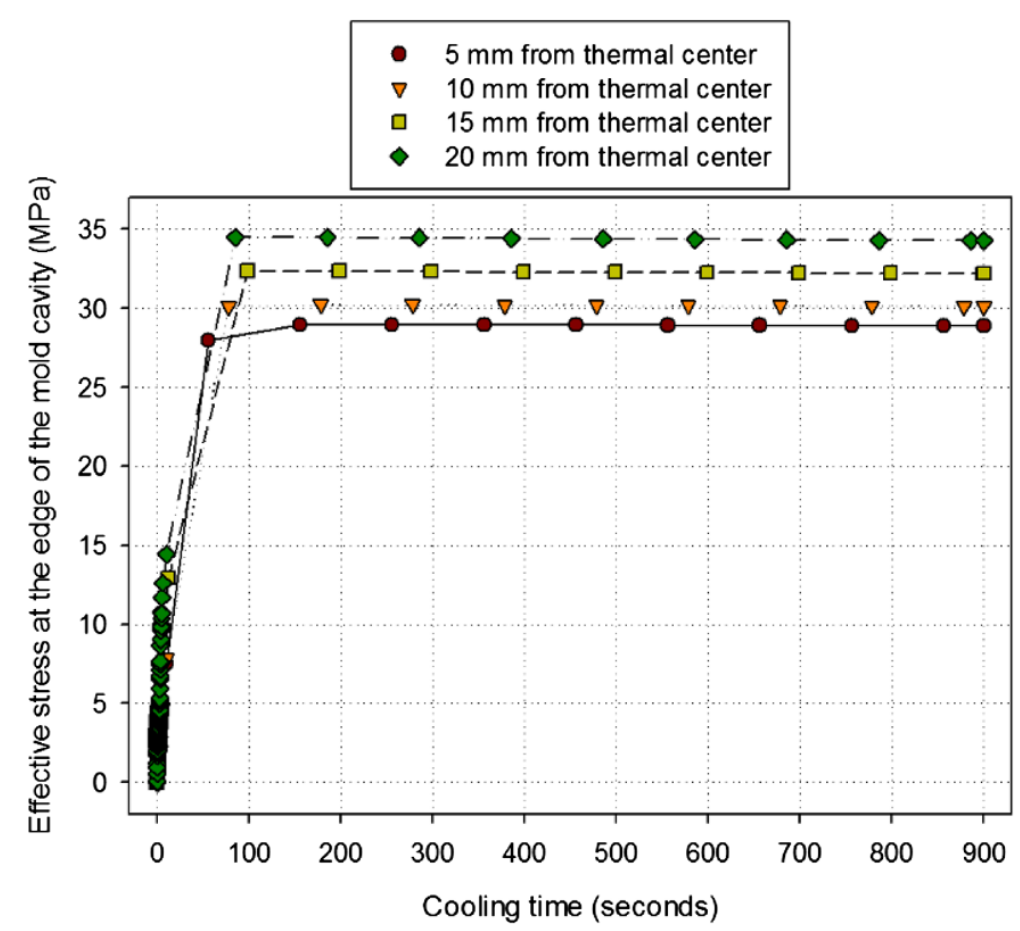

Figure 5 Stress evolution of the post at the edge of the mold cavity. Located at 5, 10, 15, and $20 \mathrm{~mm}$ from the center of the part.

Figure 5 shows that the stress evolution of the post is significantly correlated with the radial locations of the post from the center of the embossed part during cooling. The stress of the post was estimated at the edge of the mold cavity. With the increase of the radial distance of the post, the stress increased. During the first $100.0 \mathrm{~s}$ into the cooling step, the accelerated heat loss caused elevated effective stress on the embossed pattern. This could be explained by the thermal shrinkage generated during this period. Thermal shrinkage induced rapid increase of stress by pushing the embossed pattern into the left sidewall of the mold cavity due to the difference in thermal expansion between the mold insert and the polymer substrate. The maximum stresses were 28.9, 30.2, 32.3, and 34.5 $\mathrm{MPa}$ while the posts were located at $5,10,15$, and $20 \mathrm{~mm}$ from the center of the part, respectively.

From the numerical analysis, when the embossed part was cooled, it shrank from the edge toward the thermal center of the embossed part but the sidewall of a mold cavity contacting the post prevented its shrinkage. This caused thermal stress and stress concentration in the post. As the distance between the posts and thermal center increased, thermal stresses also increased since they were proportional to the amount of shrinkage of the embossed part.

Experiments were performed to validate the numerical analysis for the stress developed in the posts during cooling of hot embossing. However, the observation of cooling of the post is considered to be difficult since it

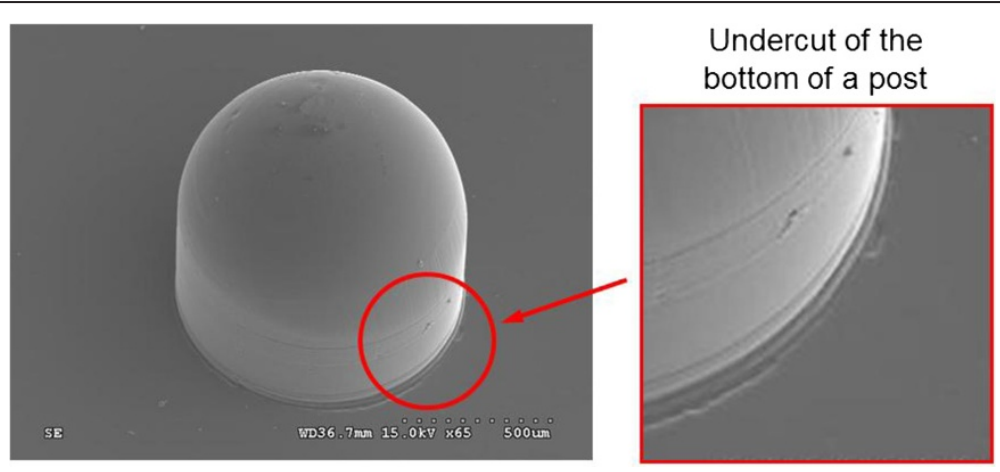

Figure 6 The SEM image of the undercut at the bottom of the post. 
requires monitoring the polymer inside the hemispheretipped hole of the mold insert. However, the defect predicted in numerical analysis can be used to validate the numerical models. The defect was observed using SEM. Figure 6 shows a SEM image of the embossed post. The undercut at the bottom of a post is evident as it was predicted in Figure 4d.

\section{Conclusions}

The stress evolution in the cooling of hot embossing was investigated for the replication of microstructures. A numerical analysis was performed to study the stress developed in the hemisphere-tipped post during cooling. Finite element models, using DEFORM-2D, predicted stress concentration at the bottom edge of the post. The results of the analysis showed that the maximum stresses were $28.9,30.2,32.3$, and $34.5 \mathrm{MPa}$ while the posts were located at 5, 10, 15, and $20 \mathrm{~mm}$ from the center of the part, respectively. The stress rapidly increased until the cooling time reached about $100.0 \mathrm{~s}$. As the radial distance of the post from the thermal center increased, thermal stresses also increased. Hot embossing experiments were conducted to validate the numerical models. The undercut at the bottom of a post is observed as it was predicted in the numerical analysis. The developed models were applicable to the design of the cooling process of micro hot embossing.

\section{Competing interests}

The authors declare that they have no competing interests.

\section{Authors' contributions}

JAG carried out the numerical analysis, designed micro hot embossing experiments, and participated in the analysis of results for the manuscript. DL assisted experimental testing and manuscript revisions. I-HS participated in the design and coordination of micro hot embossing experiments. BHY conceived the study and drafted the manuscript. All authors read and approved the final manuscript.

Received: 5 May 2014 Accepted: 26 September 2014

Published online: 11 November 2014

\section{References}

Matthew, ED, \& David, EH. (2011). Analysis and characterization of demolding of hot embossed polymer microstructures. Journal of Micromechanics and Microengineering, 21, 085024.

Song, Z, You, BH, Lee, J, \& Park, S. (2008a). Study on demolding temperature in thermal imprint lithography via finite element analysis. Microsystem Technologies, 14, 1593-1597.

Jeong, J, Choi, Y, Shin, Y, Lee, J, Park, K, Lee, E, \& Lee, S. (2002). Flow behavior at the embossing stage of nanoimprint lithography. Fibers and Polymers, 3, 113-119.

Guo, Y, Liu, G, Xiong, Y, \& Tian, Y. (2007a). Study of the demolding processimplications for thermal stress, adhesion and friction control. Journal of Micromechanics and Microengineering, 17, 9-19.

Guo, Y, Liu, G, Xiong, Y, \& Tian, Y. (2007b). Analysis of the demolding forces during hot embossing. Microsystem Technologies, 13, 411-415.

Song, Z, Choi, J, You, BH, Lee, J, \& Park, S. (2008b). Simulation study on stress and deformation of polymeric patterns during the demolding process in thermal imprint lithography. Journal of Vacuum Science and Technology, 26, 598-605.

Worgull, M, Hétu, JF, Kabanemi, KK, \& Heckele, M. (2008). Hot embossing of microstructures: characterization of friction during demolding. Microsystem Technologies, 14, 767-773.
Schift, H, Heyderman, L, Maur, MA, \& Gobrecht, J. (2001). Pattern formation in hot embossing of thin polymer films. Nanotechnology, 12, 173-177.

Worgull, M, Hétu, JF, Kabanemi, KK, \& Heckele, M. (2006). Modelling and optimization of the hot embossing process for micro- and nanocomponent fabrication. Microsystem Technologies, 12, 947-952.

Farshchian, B, Amirsadeghi, A, Hurst, SM, Kim, J, \& Park, S. (2012). Demolding behavior in 3D molding: experimental and simulation studies. Journal of Micromechanics and Microengineering, 22, 115027.

You, BH, Chen, PC, Park, DS, Park, S, Nikitopoulos, DE, Soper, SA, \& Murphy, MC. (2009). Passive micro-assembly of modular, hot embossed, polymer microfluidic devices using exact constraint design. Journal of Micromechanics and Microengineering, 19, 125025.

Jin, P, Gao, Y, Liu, T, Wang, Z, \& Zhou, H. (2009). Simulation and experimental study on recovery of polymer during hot embossing. Japanese Journal of Applied Physics, 48, 06FH10.

Juang, YJ, Lee, LJ, \& Koelling, KW. (2002a). Hot embossing in microfabrication. Part I: experimental. Polymer Engineering and Science, 42, 539-550.

Juang, YJ, Lee, LJ, \& Koelling, KW. (2002b). Hot embossing in microfabrication. Part II: rheological characterization and process analysis. Polymer Engineering and Science, 42, 551-566.

doi:10.1186/s40712-014-0020-9

Cite this article as: Gomez et al: Study on stress evolution in the cooling process of micro hot embossing. International Journal of Mechanical and Materials Engineering 2014 9:20.

\section{Submit your manuscript to a SpringerOpen ${ }^{\circ}$ journal and benefit from:}

- Convenient online submission

- Rigorous peer review

- Immediate publication on acceptance

- Open access: articles freely available online

- High visibility within the field

- Retaining the copyright to your article

Submit your next manuscript at $>$ springeropen.com 